\title{
Recruitment from pelagic to early benthic phase in lobsters Homarus americanus*
}

\author{
Lewis S. Incze ${ }^{1}$, Richard A. Wahle ${ }^{2}$ \\ ${ }^{1}$ Bigelow Laboratory for Ocean Sciences, West Boothbay Harbor, Maine 04575 , USA \\ ${ }^{2}$ Program in Ecology and Evolutionary Biology, Brown University, Providence, Rhode Island 02912, USA
}

\begin{abstract}
The abundance of neustonic postlarvae and newly recruited benthic lobsters Homarus americanus was measured for $2 \mathrm{yr}$ along the central coast of Maine, USA. Postlarvae first appeared in significant numbers in late July, rapidly increased in early August to ca 10 to $20\left(1000 \mathrm{~m}^{2}\right)^{-1}(0.5 \mathrm{~m}$ depth $)^{-1}$, then gradually declined throughout August and into early September. Late intermolt stages $D_{1}$ to $D_{3}$ characterized most of the neustonic population, with a shift in dominance to $D_{3}$ in the warmer year (1990). Postlarval abundances differed little between years: the seasonally and spatially averaged daily abundances were $5.58\left(1000 \mathrm{~m}^{2}\right)^{-1}(0.5 \mathrm{~m})^{-1} \pm 0.77$ (SE) and $6.76 \pm 1.92$ in 1989 and 1990, respectively. In contrast, there was a statistically significant difference in benthic recruitment measured in September. New recruits, lobsters with carapace length $\leq 10 \mathrm{~mm}$, averaged 1.66 ind. $\mathrm{m}^{-2} \pm 0.37$ (SE) in 1989 and $0.79 \pm 0.22$ in 1990 . Spatial patterns in recruitment density at the sampling sites were positively correlated among years $\left(\mathrm{r}_{2}=0.82\right)$ and did not appear to be related to distribution patterns of postlarvae. It seems likely that habitat type substantially influenced benthic recruitment patterns. Moreover, local differences in recruitment density of the first cohort were conserved over the 2 seasons of observation, supporting earlier assertions that new recruits are relatively sedentary. We develop a simple diagnostic model of the pelagic-to-benthic transition in lobster recruitment that accounts for the increase in density by 2 orders of magnitude from postlarval to benthic (recruit) stage, and we use this model to suggest plausible rates of postlarval diving and settlement that describe average and sitespecific recruitment in the 2 years.
\end{abstract}

\section{INTRODUCTION}

Larval settlement may be a major determinant of subsequent year-class size for many marine benthic invertebrates (Connell 1985, Gaines \& Roughgarden 1987, Davis 1988). Settlement can be affected by many factors, including abundance of the final planktonic stage, availability of appropriate settlement substrate, and physical processes (Shanks 1983, 1985, Butman 1987, Richards \& Lindemann 1987, Steger 1987, Roughgarden et al. 1988, Yashimura \& Yamakawa 1988, Sale \& Steel 1989, Lipscius et al. 1990). In addition, post-settlement mortality and movements (Hines \& Pearce 1982, Steger 1987) may obscure initial settlement patterns (McGuiness \& Davis 1989, Holm 1990). A major goal of marine ecology is to quantify these various processes, understand their sources of variability and predict population-level responses to the interaction of biotic and abiotic variables.

\footnotetext{
- Bigelow Laboratory Contribution No. 91015
}

Populations of American lobster Homarus americanus Milne Edwards are replenished by planktonic postlarvae which are mostly neustonic (Harding et al. 1982, 1987, Hudon et al. 1986). This stage undertakes diving forays to the benthos, explores the bottom and elects either to settle or to return upward (Botero \& Atema 1982, Cobb et al. 1983, 1989). Postlarvae prefer to settle in shelterproviding habitats (Botero \& Atema 1982, Cobb et al. 1983, Barshaw \& Lavalli 1988) and in nature new recruits have been found primarily in cobble substrata (Hudon 1987, Wahle \& Steneck 1991), though subtidal salt marsh peat also may be used (Able et al. 1988). Although the American lobster is a capable burrower, to date new recruits have not been found in featureless sediment (Hudon 1987, Wahle \& Steneck 1991).

Despite the commercial importance of this species and a long history of scientific study, the pelagic-tobenthic transition and early benthic life of lobsters have received little attention. The difficulty of censusing benthic recruitment habitats must be partly responsible for this. Also, even when postlarval densities are at peak, they can be 2 to 3 orders of magnitude lower than 
the density of new benthic recruits at the end of the settlement season. There is a clear need for field studies that coordinate the sampling of pelagic larvae or postlarvae with that of benthic recruits in order to understand how processes acting before and after settlement affect recruitment. In this $2 \mathrm{yr}$ study we quantify patterns of postlarval abundance and benthic recruitment at sites along the central coast of Maine, USA, and attempt to follow cohorts of lobsters through time. We propose a simple model that accounts for the accumulation of recruits given the low density of postlarvae, and we use this model to suggest future research topics.

\section{MATERIALS AND METHODS}

Study area and definitions. Johns Bay (Fig. 1) is a coastal embayment ca $5 \mathrm{~km}$ long and $3 \mathrm{~km}$ wide located along the central coast of the western Gulf of Maine. Two small rivers enter the bay but contribute little freshwater during summer months. Most of the shoreline is rocky and drops quickly to a depth of $10 \mathrm{~m}$ below MLW; below this depth fine silts and mud predominate. Most of the bay is between 10 and $40 \mathrm{~m}$ deep. Damariscove Island (Fig. 1) is ca $4 \mathrm{~km}$ long and is located $5 \mathrm{~km}$ offshore in a region of complex bathymetry. The shoreline is mostly steeply inclined bedrock, but 2 bights, one each on the east and west sides of the island, contain areas of cobble. Unlike Johns Bay, patterns of tidal flow around the island are complex and form numerous temporary tidal fronts. The tidal range averages a little over $3 \mathrm{~m}$ in the area.

The lobster postlarva (or fourth-stage lobster) is the final planktonic stage and effects the transition from pelagic to benthic life (fifth stage). The postlarva (PL) requires ca 18 to $20 \mathrm{~d}$ at temperatures of 15 to $17^{\circ} \mathrm{C}$ (MacKenzie 1985, Sasaki et al. 1986), which prevailed when most of the PLs were present in our study. After settling the PL molts to the first benthic instar. During the first few years of benthic life the lobster is restricted to shelter-providing habitats, such as cobble (Hudon 1987, Wahle 1990, Wahle \& Steneck 1991). We refer to this most habitat-restricted segment of lobster life history as the early benthic phase (EBP; Wahle \& Steneck 1991) and distinguish it from older and larger lobsters that become increasingly vagile (e.g. Krouse 1981). We operationally define EBPs as lobsters up to $40 \mathrm{~mm}$ carapace length (CL), although the transition out of this phase begins at somewhat smaller size (Hudon 1987, Wahle \& Steneck 1991). Among the EBPs we further distinguish new recruits (R), operationally defined here as lobsters $\leq 10 \mathrm{~mm}$ CL (less than $2 \mathrm{mo}$ old at the time of sampling; see 'Results').

Planktonic sampling and environmental data. In both years we collected lobster postlarvae from late July, when they first appeared, to early September, when they finally became rare. Sampling was done with a $1 \mathrm{~m}$ wide $\times 0.5 \mathrm{~m}$ deep (submerged portion) neuston sampler equipped with a $500 \mu \mathrm{m}$ mesh net. The sampling frame was a modified, light-weight (welded aluminum), $1.0 \times 0.75 \mathrm{~m}$ version of the high-

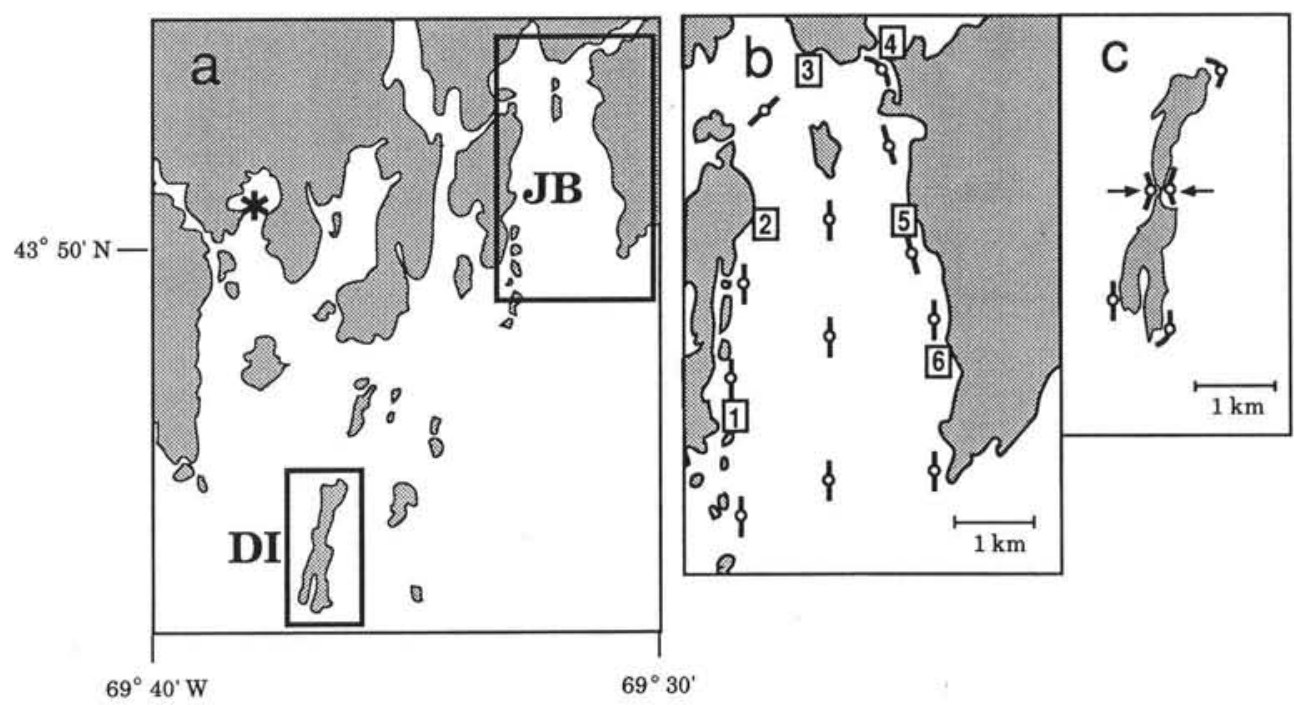

Fig. 1. (a) Overview of study area in the western Gulf of Maine, showing locations of Johns Bay (JB), Damariscove Island (DI) and the meteorological monitoring station at McKown Point (west of the asterisk). Other panels show enlargements of (b) Johns Bay and (c) Damariscove Island and sampling locations used in 1989 and 1990. Benthic sampling was conducted at sites denoted by numbered rectangles in Johns Bay and arrows at Damariscove Island; routine neuston sampling sites are shown by circles with lines that represent the length of an average tow 
speed neuston sampler of Ben-Yami et al. (1970) but without the side-tracking capability. It was towed at ca 1.6 knots $\left(80 \mathrm{~cm} \mathrm{~s}^{-1}\right)$ from the end of a $2.5 \mathrm{~m}$ boom extended orthogonally from the gunwale of a $10 \mathrm{~m}$ vessel. The sampler operated outside of any visible disturbance caused by the vessel. Aluminum skis $(1.0 \times 0.25 \mathrm{~m})$ rigidly mounted to either side of the sampler stabilized the depth of tow. Random sampling variability was investigated by repeating tows and by simultaneously towing 2 samplers from opposite sides of another vessel in 1988 and 1989.

The area sampled was estimated from a flowmeter mounted midway in the submerged portion of the net mouth; additionally, all tows were carefully timed to monitor performance of the meter and to act as a proxy when the meter fouled with seaweed or other material. Most tows were $0.5 \mathrm{~km}$ long through the water and sampled $500 \mathrm{~m}^{2}$. Tows taken near land were taken within about $40 \mathrm{~m}$ of shore. Wind direction and speed, sea state, presence of slicks and fronts, cloud cover, currents and sea surface temperature (SST) were recorded. SST data were obtained from an intake located ca $1 \mathrm{~m}$ below sea surface.

Plankton samples were collected during daytime at 12 sites in Johns Bay and 5 sites around Damariscove Island (Fig. 1). Extensive additional sampling was conducted to look at effects of wind, fronts, different water parcels, distance from shore and different shoreline features on PL abundances. We also collected samples up to $15 \mathrm{~km}$ offshore in water $>100 \mathrm{~m}$ deep. Although it is necessary to refer to some results from these varied studies, we focus here on Johns Bay and 2 sites on Damariscove Island.

Samples were sorted at sea. Lobster larvae and postlarvae were removed from each sample, placed in $8 \mathrm{oz}$. (ca $237 \mathrm{ml}$ ) jars of unfiltered seawater and stored on ice in the dark. Once back in the laboratory $(<8 \mathrm{~h}$ maximum interval for any sample), postlarvae were examined under a dissecting microscope to determine intermolt stage using criteria described by Sasaki (1984). Stages were: A, B, C, $D_{0}, D_{1}, D_{2}$, and $D_{3}$. Stage $\mathrm{D}_{1}$ was further subdivided into 3 parts $\left(\mathrm{D}_{1}{ }^{\prime}\right.$ to $\left.\mathrm{D}_{1}{ }^{\prime \prime \prime}\right)$ following Sasaki (1984). Larval stages I to III were counted but were not routinely inspected for intermolt stage. Larval data will be the subject of another paper and are not further discussed here. Postlarval abundances [no. ind. $\left(1000 \mathrm{~m}^{2}\right)^{-1}$ ] for the neuston (upper $0.5 \mathrm{~m}$ ) were calculated from the raw counts and tow data.

The total duration of postlarval development was estimated from SST data and temperature-dependent rates described by MacKenzie (1985). The duration of intermolt stages was based on developmental data from Sasaki (1984) with a temperature correction from MacKenzie's work assuming isochronally proportional adjustments.
In addition to the measurements of SST obtained at times of sampling, continuous records of SST and seabottom temperature (SBT) were available from recorders in nearby Boothbay Harbor (Fig. 1a; data collected by the Maine Department of Marine Resources laboratory). SST and SBT sensors were located at 1.7 and $7.6 \mathrm{~m}$ below mean low water, respectively. Data were recorded every $15 \mathrm{~min}$.

Benthic sampling. We assessed benthic recruitment at 8 sites in mid to late September 1989 and 1990 after postlarvae had disappeared from the neuston. Sampling was restricted to sublittoral cobble-boulder habitats. Prior extensive sampling outside these habitats (including sediment, Zostera marina beds and bedrock) failed to produce recently recruited lobsters in this area (Wahle \& Steneck 1991). Our sites ranged from 3 to $6 \mathrm{~m}$ below MLW. Six locations were chosen around the perimeter of Johns Bay (Fig. 1b), primarily to obtain representative coverage of the bay's shoreline and secondarily on the basis of similarities in the size composition of the cobble-boulder substrata (ca 10 to $50 \mathrm{~cm}$ diameter rocks). At Damariscove Island 2 sites were sampled, one each on the east and west sides.

Sampling was done by 2 divers using an airlift suction sampler at twelve $0.46 \mathrm{~m}^{2}$ quadrats at each of the sites (mean and variance stabilized at approximately 10 quadrats in earlier studies; Wahle \& Steneck 1991). Quadrats were placed haphazardly because patches of cobble varied in size from a meter to tens of meters in breadth, making predetermined random placement impractical. If the quadrat fell on a predominantly sediment patch or on a boulder that was too big to move, it was tossed again.

The airlift was a $120 \mathrm{~cm}$ length of $7.6 \mathrm{~cm}$ diameter PVC tube, with a SCUBA tank supplying air a few $\mathrm{cm}$ above the mouth of the tube. The other end of the tube was affixed to a $1.0 \mathrm{~mm}$ mesh nylon collection bag that could be removed, closed, and replaced underwater. To sample a quadrat 1 diver operated the airlift while the other assisted by removing rocks, macroalgae and lobsters too large to enter the airlift. Next, the airlift was used to excavate the cobble until no more interstitial spaces were left, which sometimes required excavating to a depth of 30 to $40 \mathrm{~cm}$. Divers worked slowly to maintain good visibility. Sample bags were returned to the surface and all lobsters were enumerated and measured.

Identifying new recruits and $1 \mathrm{yr}$ old lobsters. New benthic recruits sampled in September form a conspicuous mode in the size distribution of EBPs (see 'Results'). As conspicuous as this mode is, it is not possible to distinguish unequivocally between the larger new recruits and smaller individuals from the previous year-class. We acknowledge the inherent uncertainties of age-size estimates in crustaceans and 
hence rely on conservative application of the only method developed to date for the American lobster. We used a technique developed by Wilder (1953, p. 394) using growth data of Templeman (1948a) to give a temperature-corrected estimate of the molt stage of lobsters at a given age. Given a settlement date and a known average temperature over a period of time, we can estimate the dates of post-settlement molts. Accordingly, we estimated the stage most likely reached by recruits at the time of sampling. We compared our estimates of size-at-stage with more recent analyses of Templeman's data (Mauchline 1977), other growth studies (Hughes et al. 1972) and estimates derived from size-frequency distributions of early benthic phase lobsters from the Gulf of Saint Lawrence (Hudon 1987).

Our PL data indicate that most settlement occurred between 1 August and 1 September, and we estimate that seawater temperatures at the recruitment sites averaged 12 to $14^{\circ} \mathrm{C}$ from the time of initial settlement to the time we sampled recruits (based on the Boothbay Harbor bottom temperature record). Following Wilder's technique, most recruits in mid September should be in Stage 5 or 6 ; virtually none are expected in Stage 7. Growth studies (Templeman 1948a, b, Hughes et al. 1972) and statistical analysis of modes in sizefrequency distributions in the field (Hudon 1987) report Stage 6 smaller than $8 \mathrm{~mm} \mathrm{CL}$. Theoretical growth curves give estimates ranging from 8.0 (Hudon 1987) to $8.6 \mathrm{~mm}$ CL (Mauchline 1977) for Stage 6, based on a PL mean size of $5 \mathrm{~mm} \mathrm{CL}$. The average PL size in our study was $5.5 \mathrm{~mm}$ CL (authors' unpubl. data), resulting in Stage 6 carapace length estimates of 8.7 (following Hudon 1987) to $9.4 \mathrm{~mm}$ (following Mauchline 1977). Our limited observations of postlarvae that molted to Stage 5 in the laboratory within 1 to $3 \mathrm{~d}$ after capture agree best with Hudon's (1987) estimate of size increment for that molt. We recorded an average increase in carapace length of $11.5 \%$ (range $=11$ to $13 \%$ ), compared to Hudon's $9 \%$ and Mauchline's (1977) $31 \%$. On the basis of the above calculations and the size-frequency distributions we observed from benthic sampling, we defined new recruits as lobsters $\leq 10 \mathrm{~mm}$ CL.

One year old lobsters were defined as having a carapace length of 11 to $16 \mathrm{~mm}$. Using Wilder's technique and the average monthly bottom temperatures in our study area from 1989 to 1990 , we determined that lobsters over-wintered mostly in Stage 7, and then in the second growing season molted once or twice by September to Stages 8 and 9. Hughes et al. (1972) obtained measurements from 11 to $18 \mathrm{~mm} \mathrm{CL}$ for lobsters known to be in Stages 8 to 10. Theoretical calculations suggest a range of 13.1 to $22.3 \mathrm{~mm} \mathrm{CL}$ for these stages (Templeman 1948a, Wilder 1953, Mauchline 1977); Hudon (1987) estimated 14.5 to $23 \mathrm{~mm}$ from analysis of size-frequency distributions of wild populations. Because the size range and degree of overlap between cohorts increases with age, we conservatively define the upper limit of $1 \mathrm{yr}$ old lobsters at $16 \mathrm{~mm}$.

\section{RESULTS}

\section{Postlarvae}

Temporal patterns of PL abundance were very similar in both years: rapid increases in early August were followed by more gradual declines (Fig. 2, for Johns Bay). The same pattern was seen when averaging data from all 5 sites at Damariscove Island, although we refer only to 2 of the sites in this paper because they have corresponding benthic data. The initial increase in PL numbers was slightly later and peak abundance slightly greater in 1990 compared to 1989, but overall abundances were not statistically different (Table 1: seasonal averages in all Johns Bay and 2 Damariscove Island sites were pooled). Average PL densities at the various sites were not correlated between years (Fig. 3a).

Intermolt stages $\mathrm{A}, \mathrm{B}$ and $\mathrm{C}$ were infrequently caught. Together they comprised $100 \%$ of the few PLs caught during the third week of July 1989, but never more than $6 \%$ of PLs in August, and they occurred only at the island and offshore sites. In 1990, only a few early intermolt stages (A to C) were found in the entire season. While late intermolt (D) stages were the most prominent in both years, the relative abundance of substages $D_{1}$ to $D_{3}$ differed markedly. $D_{1}$ was present for a much shorter time and $\mathrm{D}_{2}$ and $\mathrm{D}_{3}$ for a much longer time in 1990 compared to 1989 (Fig. 4).

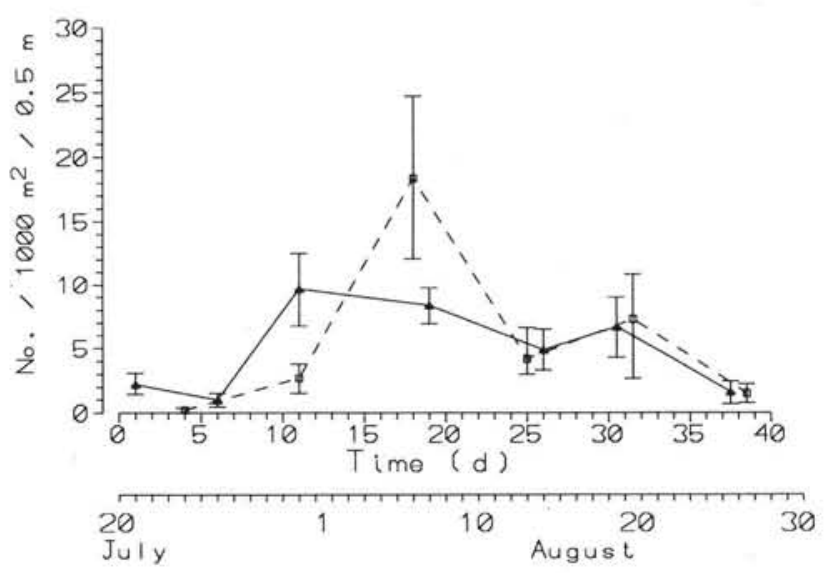

Fig. 2. Homarus americanus. Neustonic abundance of lobster postlarvae in Johns Bay during 1989 ( $\mathbf{A}-\mathbf{\Delta})$ and 1990 $(\square---\square)$. Data are means of 12 sites \pm 1 SE. Elapsed time is shown over the calendar dates. Sampling occurred on Days 31 and 38 in both years; for clarity, these data are plotted at $\pm 0.5 \mathrm{~d}$ from the day of sampling 
Table 1. Homarus americanus. Overall mean densities of postlarvae and benthic recruits in 1989 and 1990 and significance tests of between-year differences. Postlarval means were calculated from 14 planktonic sampling sites and the recruitment means from 8 benthic sampling sites

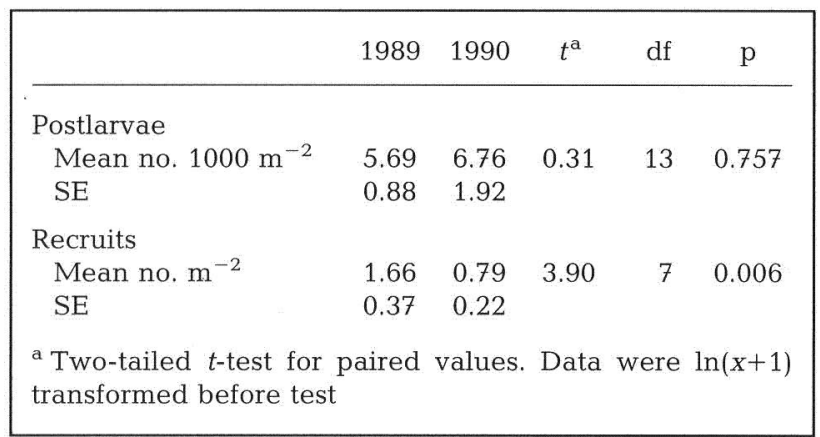

\section{Environmental temperature}

SSTs measured in Johns Bay on the sampling dates averaged $2{ }^{\circ} \mathrm{C}$ warmer during the first 2 wk of August 1990 compared to 1989; SSTs in Johns Bay during 1990 otherwise were at or slightly below 1989 measurements. Measurements from Johns Bay were in good agreement with the Boothbay Harbor continuous record of SST, which gave monthly means of 14.5 and $14.8^{\circ} \mathrm{C}$ for July 1989 and 1990 , respectively, and 15.3 and $17.0^{\circ} \mathrm{C}$ for the corresponding August temperatures. Boothbay Harbor monthly mean SBTs for August were $11.7^{\circ} \mathrm{C}$ in 1989 and $13.3^{\circ} \mathrm{C}$ in 1990 ; corresponding September SBTs for the 2 years were 12.8 and $13.8^{\circ} \mathrm{C}$. Thus, for periods relevant to postlarvae and new benthic recruits, 1990 was warmer near the sea surface by $1.7^{\circ} \mathrm{C}$ during August and at depth by $1.3^{\circ} \mathrm{C}$ during August and September. Bottom temperatures experienced by the 1989 year-class from September 1989 to September 1990 can be summarized as follows: a gradual decline to a monthly mean of $3.0^{\circ} \mathrm{C}$ in December; monthly means at or below $3.0^{\circ} \mathrm{C}$ through March; $4^{\circ} \mathrm{C}$ in April; and gradual increases to the seasonal high of $13.8^{\circ} \mathrm{C}$ the following September.

\section{Early benthic phase lobsters}

New benthic recruits formed a clear mode at 7 to $8 \mathrm{~mm} \mathrm{CL}$ in the size distributions of lobsters sampled from all sites in September of both years (Fig. 5). There was a large and statistically significant interannual difference in recruitment densities using the criterion of $10 \mathrm{~mm} \mathrm{CL}$ (Table 1). While the density of new recruits in 1990 averaged only $40 \%$ of the 1989 recruitment (Table 1), the density of the total EBP populations

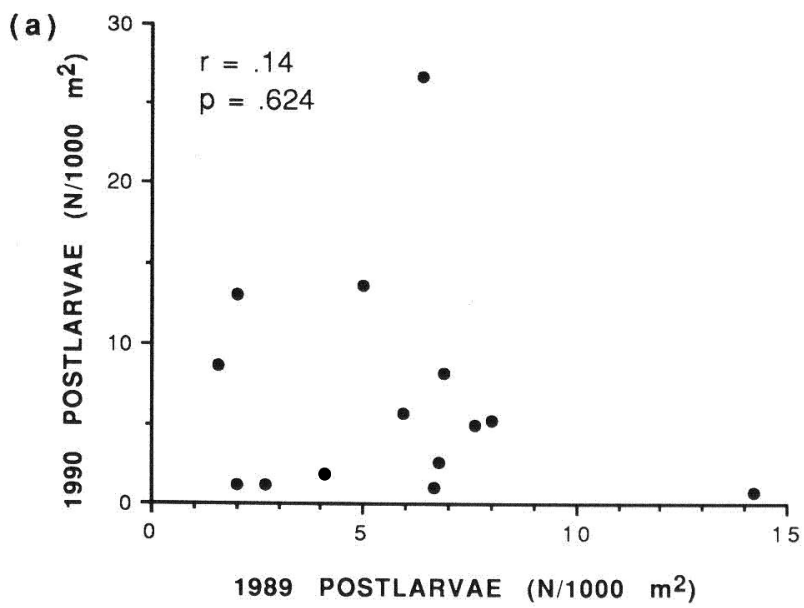

(b)

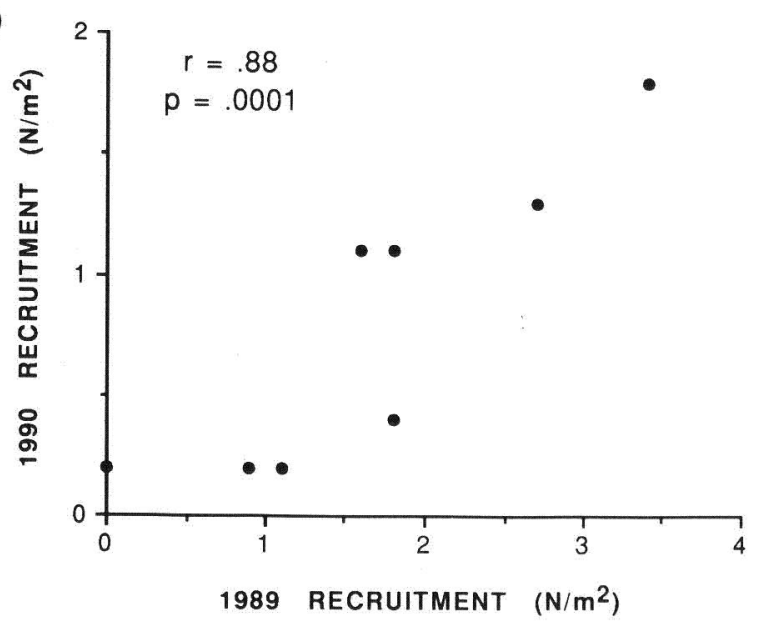

Fig. 3. Homarus americanus. Scatterplots and between-year correlation coefficients for (a) postlarval densities (seasonal averages at each of 14 sites) and (b) benthic recruitment ( 8 sites). Local recruitment densities for the 2 years are significantly correlated, while postlarval densities are not

did not change much. In 1989, new recruits [1.7 ind. $\left.\mathrm{m}^{-2} \pm 0.4(\mathrm{SE})\right]$ comprised about one third of all EBPs $\left(4.9 \pm 0.7\right.$ ind $\left.\mathrm{m}^{-2}\right)$ at the cobble sites, whereas in 1990 they comprised only about one fifth $(0.8 \pm 0.2$ vs $4.2 \pm$ 0.9 ind. $\mathrm{m}^{-2}$ ).

In both 1989 and 1990, the highest and lowest population densities of recruits (Fig. 6) and older EBPs (Table 2) were found on opposite sides of Damariscove Island (west and east respectively). The spatial pattern of recruitment density among all sites was positively correlated (Fig. 3b) but did not show a consistent relationship to patterns of PL abundance (Fig. 7a: seasonally averaged for each site).

There was a significant correlation between the density of recruits in 1989 and 1 yr old EBPs sampled in 1990 (Fig. 7b); thus, the pattern established by initial recruitment was maintained over the first year of 


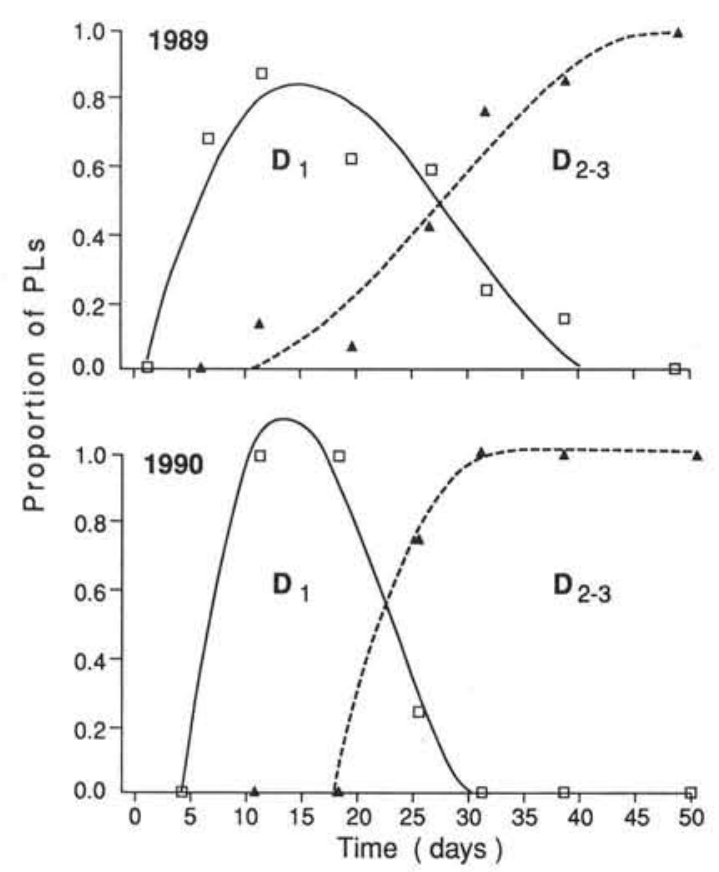

Fig. 4. Homarus americanus. Late intermolt stage $\left(\square, D_{1} ; \mathbf{\Delta}, D_{2}\right.$ to $D_{3}$ ) composition of lobster postlarvae (PL) in Johns Bay during 1989 and 1990. Data are fit with polynomial equations to provide daily proportions used in the recruitment model

benthic life. The average density of the 1989 year-class declined from $1.66 \pm 0.37$ to $1.38 \pm 0.54$ ind. $\mathrm{m}^{-2}$ from September 1989 to September 1990, but the means do not differ significantly (2-tailed $t$-test for paired values: $t=1.96, \mathrm{df}=7, \mathrm{p}=0.90$ ).

\section{Computation of settlement rates}

We formulated a simple recruitment model to quantitatively link observations of lobster postlarvae and new benthic recruits in Johns Bay for 1989 and 1990. Johns Bay was selected because of its simpler hydrographic and tidal conditions, its more confined geography, and the quantity of benthic and planktonic data available. The model is based on having to produce the observed final outcome (densities of new recruits) at known recruitment sites when constrained by the estimated daily abundances of PLs in surface waters. We purposely avoided having to specify advection rates or make assumptions about the proportion of suitable habitat in the bay. The model is not concerned with how PLs got to the overlying water column, though this is relevant to the investigation and will be discussed later. The model can be used to explore the combination of functions (e.g. diving of PLs, successful benthic settlement) that must have existed in order to link the
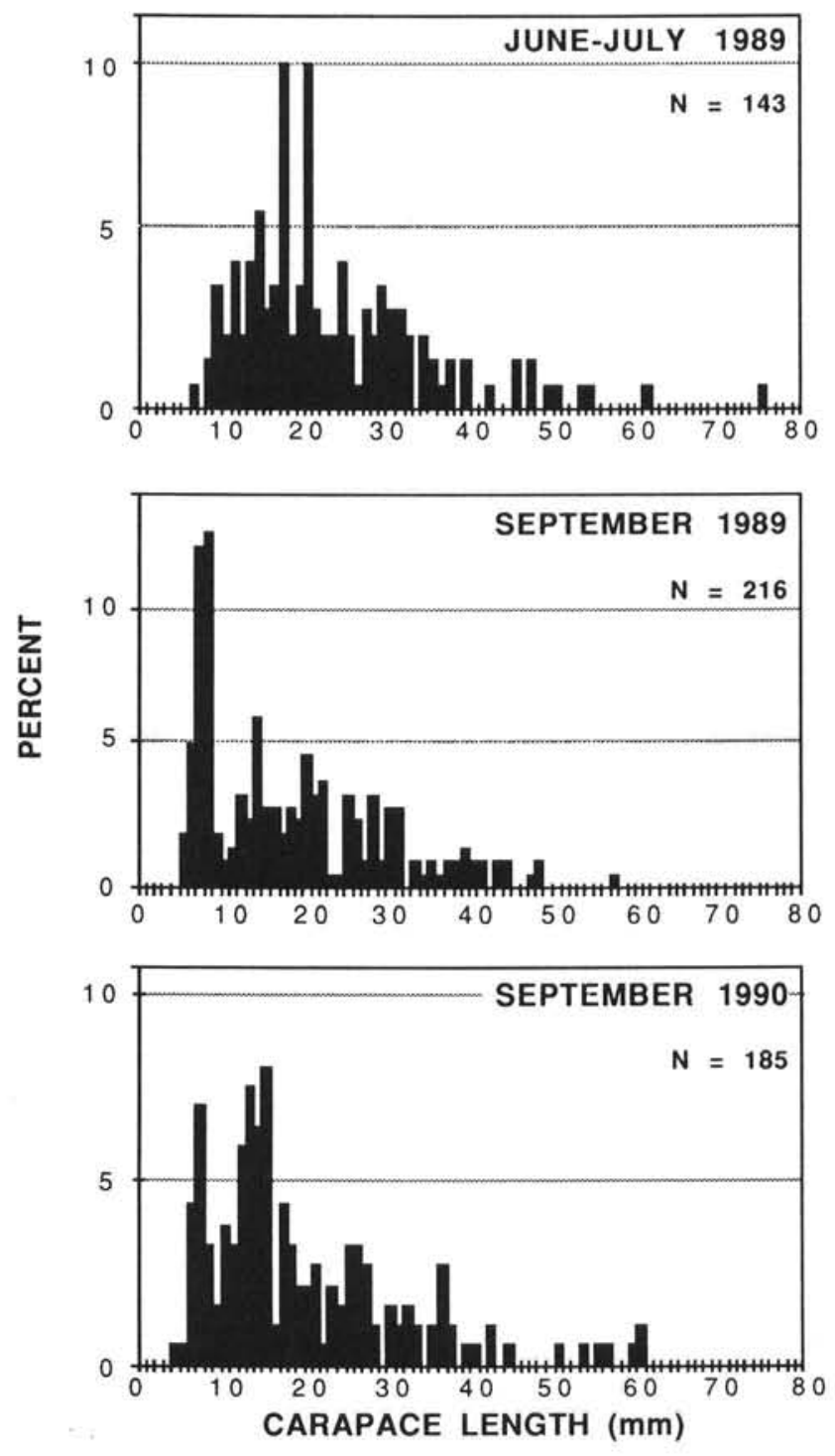

Fig. 5. Homarus americanus. Size-frequency distribution of benthic lobsters before (June) and after (September) settlement. Data were pooled from the 8 benthic sites shown in Fig. 1. The 1989 year-class appears to be present in the mode from 11 to $16 \mathrm{~mm}$ CL in the September 1990 size distributions

pelagic and benthic phases. We examined the effects of varying assigned values for the rate functions (e.g. diving frequencies) or conditions (such as daily PL abundances) and we evaluated the rates of advection required to satisfy the modeled linkages.

The following variables and assumptions were used in the model formulation.

\section{Variables:}

$R$ : Final average density of new benthic recruits, as no. $\mathrm{m}^{-2}$, from the 6 sampling sites in Johns Bay.

$P L$ : Daily abundance of PLs, as no. $\left(1000 \mathrm{~m}^{2}\right)^{-1}$, de- 


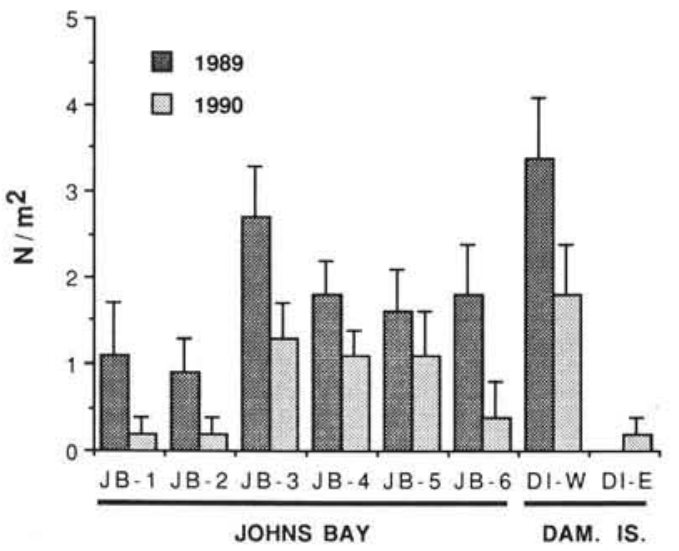

Fig. 6. Homarus americanus. Local (spatial) and interannual variation in benthic recruitment $( \pm 1 \mathrm{SE})$ in cobble substratum at Johns Bay (JB, sites 1 to 6 ) and Damariscove Island (DI, west and east), September 1989 and 1990

Table 2. Homarus americanus. Densities of 1 yr old lobster at all sampling sites in 1990 compared to recruitment dynamics. Right-hand column gives the percentages of reduction in 1990 compared to 1989. Sites are shown in Fig. 1. JB: Johns Bay; DI-W, DI-E: Damariscove Island west and east. The DI-E site showed a small increase from zero recruits in 1989 (cf. Fig. 6)

\begin{tabular}{|lcc|}
\hline $\begin{array}{l}\text { Sampling } \\
\text { site }\end{array}$ & $\begin{array}{c}\text { Density of } 1 \text { yr olds } \\
\text { (no. } \mathrm{m}^{-2} \text {, } \\
\text { mean } \pm 1 \text { SE) }\end{array}$ & $\begin{array}{c}\text { Reduction in no. } \\
\text { recruits } \mathrm{m}^{-2} \\
1989 \text { to } 1990(\%)\end{array}$ \\
\hline JB-1 & $0.4 \pm 0.1$ & 82 \\
JB-2 & $0.1 \pm 0.1$ & 78 \\
JB-3 & $1.1 \pm 0.2$ & 52 \\
JB-4 & $0.7 \pm 0.3$ & 39 \\
JB-5 & $0.4 \pm 0.2$ & 31 \\
JB-6 & $0.3 \pm 0.2$ & 78 \\
DI-W & $2.2 \pm 0.5$ & 47 \\
DI-E & $0 \pm 0$ & - \\
\hline
\end{tabular}

rived from best fit equations to the weekly mean neustonic abundances $\left(\mathrm{r}^{2}>0.90\right)$.

$F_{\mathrm{e}}$ : Excursion frequency: frequency of PL departures (dives) from the surface in search of bottom habitat, as no. ind. ${ }^{-1} \mathrm{~h}^{-1}$.

$P_{\mathrm{tr}}$ : Proportion of PLs leaving the surface that transit the full water column and recruit successfully to the benthos, an aggregated proportion that is a product of the following:

(i) proportion of dives from the surface that are continued all the way to the bottom, $P_{\text {bot }}$ (i.e., the proportion of surface dives that results in encounters with the bottom, as determined by behavior and survival);

(ii) proportion of PLs that settle in a cobble habitat after encountering it, $P_{\text {set }}$ (i.e., the proportion of PLs encountering the bottom that then survive the benthic exploration process and elect to settle at the site); and
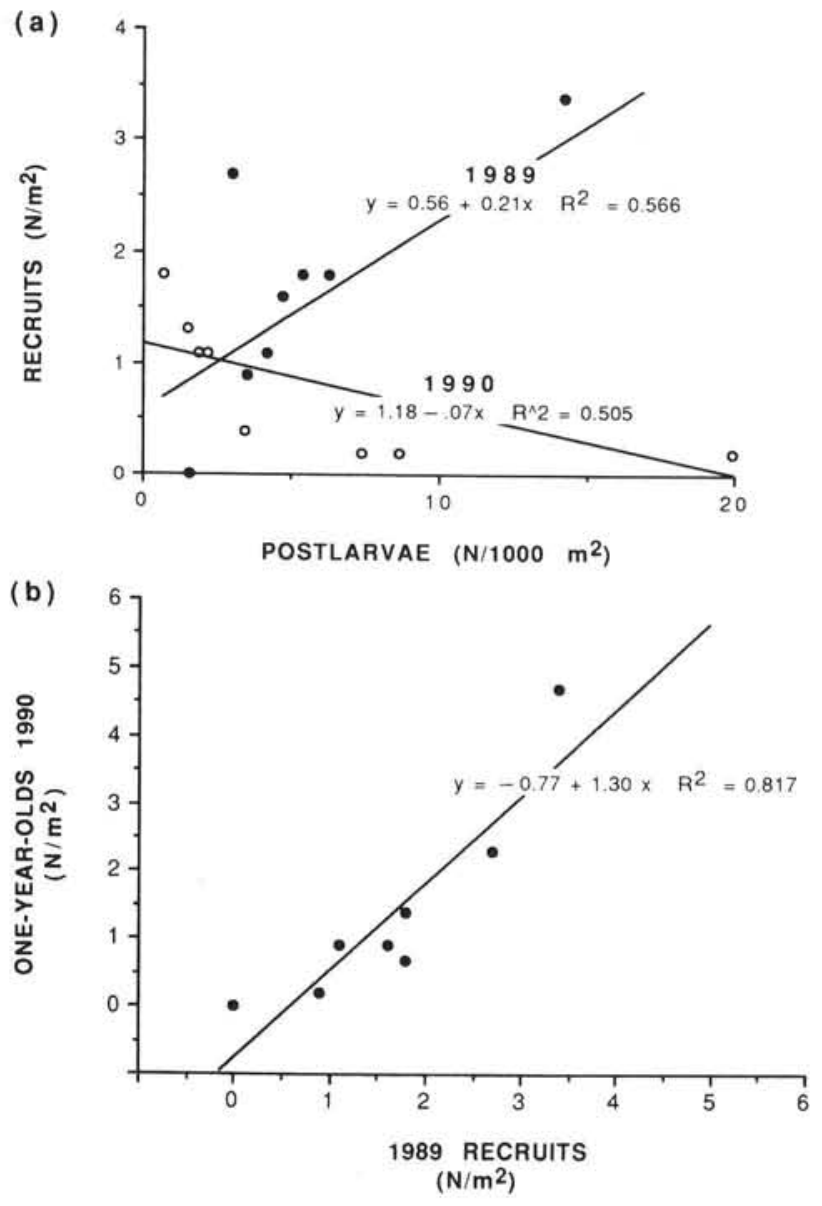

Fig. 7. Homarus americanus. Fate of lobster cohorts through time. (a) Postlarval densities vs recruitment in 1989 (•) and 1990 (O); Johns Bay. Postlarval densities were averaged for pairs of tow sites nearest each of the 6 benthic sites. (b) Density of the 1989 year-class shortly after settlement vs density at the same sites 1 yr later; Johns Bay and Damariscove Island

(iii) proportion of new benthic recruits that survive until sampled in middle to late September, $P_{\text {sur. }}$.

Initial assumptions:

(1) PLs initiate diving (bottom searching) behavior at $\mathrm{D}_{1}$ (Cobb et al. 1989) and are competent to settle (Botero \& Atema 1982). (Cobb et al. 1989 show that diving can begin at Stage $C$, but few lobsters in Stage $\mathrm{C}$ or $\mathrm{D}_{0}$ were found in Johns Bay.)

(2) All postlarval stages from $D_{1}$ onward dive with the same frequency $\left(F_{\mathrm{e}}\right)$ and have the same proclivity to swim to the bottom at a given site (part of the variable $\left.P_{\text {bot }}\right)$ and settle if suitable habitat is encountered $\left(P_{\text {set }}\right)$. We presently lack information required to assume otherwise; this limitation applies also to the assumptions below.

(3) All postlarval stages from $D_{1}$ onward are equally susceptible to predation. 


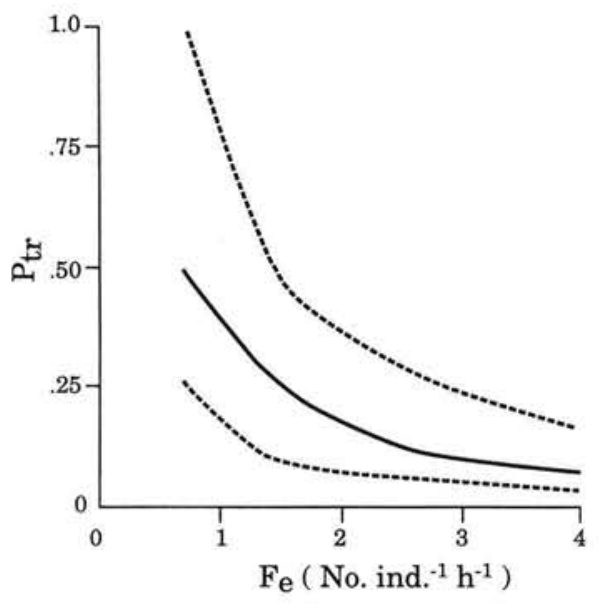

Fig. 8. Homarus americanus. Modeled relationship between postlarval diving frequency $\left(F_{\mathrm{e}}\right)$ and proportion of diving postlarvae successfully recruiting to the benthos $\left(P_{\mathrm{tr}}\right)$ in Johns Bay, 1989. The relationship is based on dives conducted over suitable habitat and is constrained by observed values of $P L$ and $R$. Continuous line shows the relationship necessary to meet the average recruitment density measured in middle September; dashed lines show corresponding values for the maximum and minimum densities observed

(4) $F_{\mathrm{e}}$ and $P_{\mathrm{tr}}$ do not change on a diel basis.

The model sums the products of the variables over a $50 \mathrm{~d}$ period:

$$
R=\sum_{0}^{50} P L \times 24 F_{\mathrm{e}} \times P_{\mathrm{tr}}
$$

Fifty days includes the tails of the PL abundance curves and allows for years (or locations) in which PLs might have a more protracted development than in our study. Two quantities, $P L$ and $R$, were prescribed by the data, leaving 2 variables that were unknown: $F_{\mathrm{e}}$ and $P_{\mathrm{tr}}$. Fig. 8 depicts the modeled relationship between these 2 unknowns. The following numbers are given as examples of the model output. If values of $R$ for Johns Bay in 1989 are used (mean $R=1.7$ ind. $\mathrm{m}^{-2}$; range $=0.9$ to 3.4$)$, and if $F_{\mathrm{e}}=1.5$ ind. $^{-1} \mathrm{~h}^{-1}$, the calculated average $P_{\text {tr }}$ is 0.24 (range $=0.09$ to 0.47 ). This calculation suggests that if $F_{e}=1.5$, then on a bay-wide average $24 \%$ of the PLs that encountered cobble bottom successfully recruited there, but the range of settlement probabilities among sites appears large. Conversely, if we assume that $P_{\mathrm{tr}}$ was a constant 0.24 at all sites (i.e., all sites experienced the same rate of recruitment once a PL left the neuston), then it can be seen that $F_{\mathrm{e}}$ must have varied considerably (from 0.75 to 2.9 dives ind. ${ }^{-1} \mathrm{~h}^{-1}$ ) in order to account for the observed site-specific differences in $R$. As the frequency of surface excursions increases beyond 3 per hour the range of values for $P_{\mathrm{tr}}$ decreases considerably. Lower values of $P_{\mathrm{tr}}$ require larger ranges of excursion frequency among sites to balance the equation for $P L$ and $R$.

A similar set of calculations was made using data from 1990, assuming, as above, that postlarvae were homogeneously distributed with respect to the recruitment sites. Although the relationship is similar to that illustrated for 1989, lower values of $P_{\mathrm{tr}}$ and $F_{\mathrm{e}}$ are indicated. For comparison: with $F_{\mathrm{e}}$ at 1.5 ind. $\mathrm{h}^{-1}$, the lower $R$ observed in 1990 (mean $=0.8$ ind. $\mathrm{m}^{-2}$; range $=0.2$ to 1.8 ) indicates an average $P_{\mathrm{tr}}$ of 0.10 (range $=$ 0.025 to 0.22 ). If the average $P_{\mathrm{tr}}$ thus calculated were assumed to exist at all sites, then the corresponding values for $F_{\mathrm{e}}$ would range from 0.15 to 1.4 dives ind. ${ }^{-1}$ $\mathrm{h}^{-1}$ in order to explain site-specific differences in $R$.

Differences in recruitment, $R$, between years cannot be explained by the average abundance of PLs alone. If we solve for $R$ using the $1990 \mathrm{PL}$ abundance data and bay-wide values of $F_{\mathrm{e}}$ and $P_{\mathrm{tr}}$ derived from 1989 (Fig. 8), we predict virtually no difference in recruitment between the 2 years, a prediction at odds with the findings. Possible explanations, including potential problems with identification of benthic year-classes, are presented in the 'Discussion' section.

The model indicates that benthic recruitment is a protracted process not substantially affected by shortterm variations in PL abundance (Fig. 9). Taking the maximum PL densities observed during the field studies and adding them in the model to the various sites where they occurred had only a small impact on calculations performed by the model (e.g. settlement). The effect also was small when PL abundance curves were periodically 'spiked' (e.g. every other day) by an amount equal to the average variance observed among sites on the 2 nearest sampling dates.

The modeled daily recruitment rates were examined

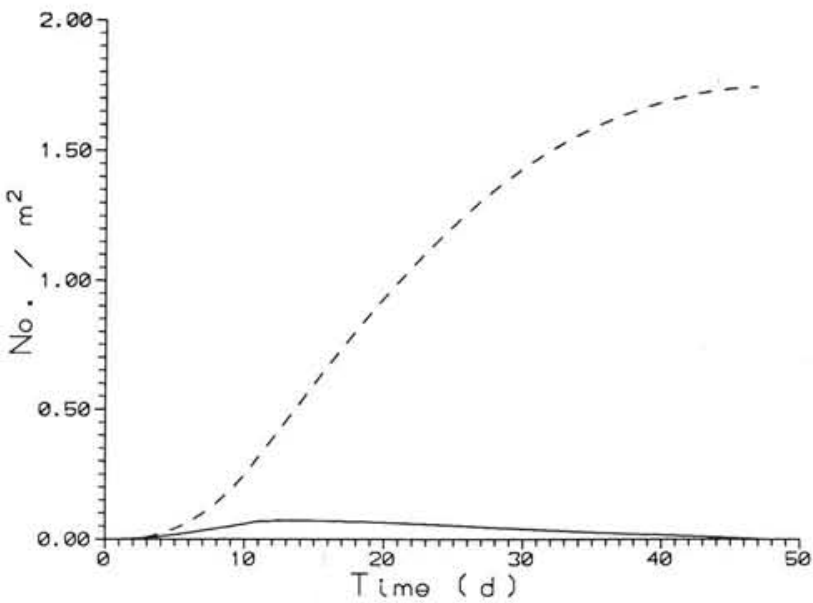

Fig. 9. Homarus americanus. Daily (-) and cumulative (---) recruitment curves fit by the model. Curves are based on the average daily postlarval standing stocks and average seasonal recruitment in Johns Bay in 1989 
to see what minimum advection rates they would require in order to maintain the necessary supply of PLs over the recruitment sites. The average rates of advection for the situation in 1989 always were small $\left(<0.2 \mathrm{~cm} \mathrm{~s}^{-1}\right)$ compared to rates available from tidal and wind forcing. Another test of the reasonableness of the model was made by comparing the average daily decline in PL abundance $\left(5 \% \mathrm{~d}^{-1}\right.$ after the peak in early August 1989) with the predicted settling rate (based on the bay-wide average of $R$ ) using generous assumptions about the amount of cobble recruitment habitat in the bay ( $20 \mathrm{~m}$ wide for $16 \%$ of the shoreline length, based on inspection of shoreline and sublittoral morphology). The number of PLs required to satisfy these estimates accounts for a 0.70 to $0.85 \% \mathrm{~d}^{-1}$ decline in the standing stocks of PLs in Johns Bay, or 14 to $17 \%$ of the average total daily decline. By this estimate, more than $80 \%$ of the daily decline of PLs in the bay was due to factors other than recruitment to cobble habitats.

\section{DISCUSSION}

This study is the first attempt to examine quantitatively the relationship between patterns of postlarval abundance and patterns of benthic recruitment in the American lobster. Since our techniques enable us to census benthic recruits very soon after settlement, we can distinguish new recruits from older segments of the population. In addition, it may be possible to follow the fate of a cohort for a limited amount of time. It has been suggested that the number of postlarvae below the top $0.5 \mathrm{~m}$ probably is small (Harding et al. 1982, Hudon et al. 1986) and would have a correspondingly small impact on the calculations performed here (but see also Harding et al. 1987). None of the PLs that we watched while sampling exhibited an escape response from the sampler, and our coverage of the area and of hydrographic features was quite thorough over the course of 2 seasons. Thus, we believe we have obtained reasonable estimates of PL abundance, particularly for Johns Bay. The efficiency with which we could obtain neustonic samples was important for conducting this study; nonetheless, more information on the vertical distributions and behavior of PLs is needed to better understand recruitment mechanisms and to improve on the calculations we perform here.

Our data show that the spatial pattern of benthic recruitment was remarkably similar from one year to the next. The simplest interpretation is that habitat quality is an important determinant of settlement pattern. To resolve this question requires that we understand how the $P_{\text {set }}$ and $P_{\text {sur }}$ terms in the model are affected by the habitat that PLs encounter when they search the bottom and attempt to settle. In addition, we must consider if $F_{\mathrm{e}}$ and $P_{\text {bot }}$ differ spatially and how they are regulated, because these factors will affect the rate of exposure of bottom habitat to exploration by PLs. For example, the proportion of PLs reaching the bottom $\left(P_{\text {bot }}\right)$ might be affected by postlarval responses to hydrographic conditions or by pelagic predators. An alternative explanation for the pattern of recruitment is that it was established by spatial patterns in the abundance of PLs and that these were very similar in the 2 years, but our data do not support this and we think it is unlikely. We interpret the absence of interannual correlation of PL abundances among sites (Fig. 3a) and the lack of a consistent relationship between $P L$ and $R$ (Fig. 7a) to be indicative of highly variable PL distributions on the scale of distances separating sampling stations in this study. Tides and wind forcing are 2 factors likely to affect these distributions on short time scales, but much greater frequency of sampling, or adequate modeling, is required to understand these patterns. In the meantime it is necessary to consider bay-wide averages of PL abundance.

The model indicates that transient changes in PL abundance do not have a major influence on recruitment because settlement is a relatively gradual process. This prediction is consistent with field observations from 1990. Data from that year show very high concentrations of PLs along the western side of Johns Bay and extremely low concentrations elsewhere on 3 sampling days when the wind was blowing from the east (Incze unpubl.). These events occurred when PLs were abundant and in late intermolt stages, but there was no increase in final recruitment density on the western compared to other shores (Fig. 6). The apparent relationship between wind and PL distributions does suggest, however, that a model of advection could be used to reconstruct PL distribution patterns in places such as Johns Bay and could help in evaluating the relative roles that PL supply and other factors had in determining the observed pattern of recruitment. Data from the 2 sides of Damariscove Island indicate that PL supply might be an issue in some locations.

We found significant interannual differences in lobster recruitment, although no such difference existed in average PL abundance. It is unclear what mechanism(s) would explain the reduction at virtually all sites in 1990 . We first considered the possibility that recruitment in 1990 was inhibited by presence of the previous year-class: in comparison, the 1989 recruits encountered a much lower density of $1 \mathrm{yr}$ old lobsters at the time of their settlement (see Fig. 5). We noted earlier that the average density of all EBPs did not differ much between the 2 years, even though the size composition did. This supports the idea of density-dependent interactions, but these are not readily extracted from our data because the capacity of each site to accomo- 
date various benthic stages probably differs. This is suggested by absence of a consistent relationship between the density of $1 \mathrm{yr}$ old lobsters and the reduction in recruitment at individual sites (Table 2). Thus, density dependence remains a plausible but untested explanation. We also considered whether our size criterion was at fault. We have gone carefully over the expected molt frequencies and sizes of newly recruited lobsters. With the earlier settlement and faster growth expected in 1990 due to warmer temperatures, we expected a greater frequency of Stage 6 lobsters in September 1990 compared to September 1989, but new recruits still should not have exceeded our size criterion of $10 \mathrm{~mm} \mathrm{CL}$ except in rare cases. By their nature size criteria are not perfect, but we feel the error that might be introduced in the present case is small compared to differences in estimated recruitment between years, and we conclude that the interannual difference probably was real and not an artifact.

Several alternative hypotheses for reduced recruitment in 1990 could be proposed. For example, it might be argued that warmer temperatures, hence faster development, reduced the time available for PLs to seek suitable habitat. Similar standing stocks and faster development might have resulted in a higher flux of available PLs in 1990, but if this occurred it did not result in greater benthic recruitment. Other possibilities, such as behavior or condition of the postlarvae, hydrographic conditions such as stratification, or abundance and activity of predators, also exist. None can be addressed by our data but should be considered in the future. These factors would manifest themselves in the variables $F_{\mathrm{e}}$ and $P_{\mathrm{tr}}$ described in the model, and both are amenable to experimentation.

Our data suggest that lobster cohorts are not subject to strong density-dependent controls during the first year of benthic life. Density-dependent effects are not best tested in this manner and in any case may be difficult to detect (Holm 1990), but it is clear that the spatial pattern of high and low recruitment densities tended to be preserved during this period (Fig. $7 \mathrm{~b}$ ) and that the average density did not decline much. This is not to say that density-dependent changes will not occur as members of the cohort continue to grow (cf. Caddy 1986). Recruitment densities at some of our sites are among the highest reported, so if lobsters are subject to densitydependent controls during the early benthic phase, this should become evident with continued sampling.

Our model is intentionally simple at this time. By focusing on small units of area at known recruitment sites we were able to concentrate on the quantitative relationships involved in the vertical flux of PLs to the bottom. We avoided having to make initial assumptions about the total area over which recruitment was taking place or about rates of advection. We demonstrated a posteriori that advection within the bay was not limiting in our scenario and that a generous hypothetical estimate of the bay's total recruitment was not unrealistically large compared to the bay's daily standing stock of PLs. We emphasize that our calculations are based on local standing stocks and not on the population of PLs; the larger role of advection in supplying PLs to Johns Bay must be explored further. By aggregating functions in the model into just 2 terms, $F_{\mathrm{e}}$ and $P_{\mathrm{tr}}$, we were able to describe reasonable estimates for each based on present knowledge. Our initial assumption that PLs do not show significant diel differences in behavior must be investigated, however, not only for the information it will provide on how lobsters recruit, but also for its impact on the rates of $F_{\mathrm{e}}$ and $P_{\mathrm{tr}}$ calculated here. For example, if daytime sampling underestimates PL abundance, then the rates are overestimated; if diving and/or bottom searching change on a diel basis, this also must be factored into the model. When employed in a diagnostic manner, the model should be transposable to other areas where $R$ is measured and $P L$ can be estimated with reasonable confidence. Until more is known about factors influencing $F_{\mathrm{e}}$ and the component functions of $P_{\text {tr }}$, however, the model cannot be used to predict $R$ except for comparative exercises, as we did here in comparing 'predicted' vs actual recruitment densities in 1990. We did not attempt to quantify component variables such as $P_{\text {bot }}$ because we had no data with which to constrain their values. We separated them because we believe it will be useful in future work to consider the environmental and developmental factors that influence these individual functions.

Acknowledgements. We thank T. Ainaire, D. Meisenheimer and R. Wakelin for their help in the field and laboratory; the Maine Department of Marine Resources, especially D. Smith, for temperature data; S. J. Cobb and R. S. Steneck for discussions; M. Dunn for boat operations; and S. J. Cobb, M. Fogarty, L. Botsford and D. Campbell for comments on the original manuscript. This work was supported by grants from the University of Maine Sea Grant Program and by a grant from the Lobster Institute at the University of Maine.

\section{LITERATURE CITED}

Able, K. W., Heck, K. L., Fahay, M. P., Roman, C. T. (1988). Use of salt marsh peat reefs by small juvenile lobsters on Cape Cod, Massachusetts. Estuaries 11: 83-86

Barshaw, D. E., Lavalli, K. L. (1988). Predation upon postlarval lobsters Homarus americanus by cunners Tautogolabrus adspersus and mud crabs Neopanope sayi on three different substrates: eelgrass, mud and rocks. Mar. Ecol. Prog. Ser. 48: 119-123

Ben-Yami, M., Herzberg, A., Pisanty, S., Lourie, A. (1970). A side-tracking neuston net. Mar. Biol. 6: 312-316

Botero, L., Atema, J. (1982). Behavior and substrate selection during larval settling in the lobster Homarus americanus. J. crust. Biol. 2: 59-69 
Butman, C. A. (1987). Larval settlement of soft-sediment invertebrates: the spatial scales of pattern explained by active habitat selection and the emerging role of hydrodynamical processes. Oceanogr. mar. Biol. A. Rev. 25: 113-164

Caddy, J. F. (1986). Modelling stock-recruitment processes in Crustacea: some practical and theoretical perspectives. Can. J. Fish. Aquat. Sci. 43: 2330-2344

Cobb, J. S., Gullbranson, T., Phillips, B. F., Wang, D., Syslo, M. (1983). Behavior and distribution of larval and early juvenile Homarus americanus. Can. J. Fish. Aquat. Sci. 40: 2184-2188

Cobb, J. S., Wang, D., Campbell, D. B. (1989). Timing and settlement by postlarval lobsters (Homarus americanus): field and laboratory evidence. J. crust. Biol. 9: 60-66

Connell, J. H. (1985). The consequences of variation in initial settlement vs post-settlement mortality in rocky intertidal communities. J. exp. mar. Biol. Ecol. 93: 11-45

Davis, A. R. (1988). Effects of variation in initial settlement on distribution and abundance of Podoclavella muluccensis Sluiter. J. exp. mar. Biol. Ecol. 117: 157-167

Gaines, S. D., Roughgarden, J. (1987). Fish in offshore kelp forests affect recruitment to intertidal barnacle populations. Science 235: 479-481

Harding, G. C., Pringle, J. D., Vass, W. P., Pearre, S. Jr, Smith, S. J. (1987). Vertical distribution and daily movements of larval lobsters Homarus americanus over Browns Bank, Nova Scotia. Can. J. Fish. Aquat. Sci. 41: 29-41

Harding, G. C., Vass, W. P., Drinkwater, K. F. (1982). Aspects of larval American lobster (Homarus americanus) ecology in St, Georges Bay, Nova Scotia. Can. J. Fish. Aquat. Sci. 39: $1117-1129$

Hines, A. H., Pearce, J. S. (1982). Abalones, shells and sea otters: dynamics of prey populations in central California. Ecology 63: 1547-1560

Holm, E. R. (1990). Effects of density-dependent mortality on the relationship between recruitment and larval settlement. Mar. Ecol. Prog. Ser, 60: 141-146

Hudon, C. (1987). Ecology and growth of post-larval and juvenile lobster, Homarus americanus, off ile de la Madeleine (Quebec). Can. J. Fish. Aquat. Sci. 44: 1855-1869

Hudon, C., Frechette, P., Legendre, P. (1986). La repartition horizontale et verticale des larves de homard (Homarus americanus) autour des iles de la Madeleine, golfe du St. Laurent. Can. J. Fish. Aquat. Sci. 43: 2164-2176

Hughes, J. T., Sullivan, J. J., Schleser, R. (1972). Enhancement of lobster growth. Science 177: 1110-1111

Krouse, J. S. (1981). Movement, growth and mortality of American lobsters, Homarus americanus, tagged along the coast of Maine. NOAA Tech. Rep. NMFS-SSRF 747. U.S. Dept Commerce, Washington, D.C., 12 p.

Lipscius, R. N., Olmi, E. J. III, van Montfrans, J. (1990). Planktonic availability, molt stage and settlement of blue crab postlarvae. Mar. Ecol. Prog. Ser. 58: 235-242

MacKenzie, B. R. (1985). Assessment of temperature effects on

This article was presented by K. Sherman, Narragansett, Rhode Island, USA interrelationships between stage durations, mortality, and growth in laboratory-reared Homarus americanus Milne Edwards. J. exp. mar. Biol. Ecol. 116: 87-98

Mauchline, J. (1977). Growth of shrimps, crabs and lobsters an assessment. J. Cons. int. Explor. Mer 37: 162-169

McGuiness, K. A., Davis, A. R. (1989). Analysis and interpretation of the recruit-settler relationship. J. exp. mar. Biol. Ecol. 134: 197-202

Richards, W. J., Lindeman, K. C. (1987). Recruitment dynamics of reef fishes: planktonic processes, settlement and demersal ecologies, and fishery analysis. Bull. mar. Sci. 41: $392-410$

Roughgarden, J., Gaines, S., Possingham, H. (1988). Recruitment dynamics in complex life cycles. Science 241: $1460-1466$

Sale, P. F., Steel, W. J. (1989). Temporal variability in patterns of association among fish species on coral patch reefs. Mar. Ecol. Prog. Ser. 51: 35-47

Sasaki, G. (1984). Biochemical changes associated with the embryonic and larval development in the American lobster Homarus americanus Milne Edwards. Ph.D. dissertation, Woods Hole Oceanographic Inst., Woods Hole

Sasaki, G. C., Capuzzo, J. M., Biesot, P. (1986). Nutritional and bioenergetic considerations in the development of the American lobster Homarus americanus. Can. J. Fish, Aquat. Sci. 43: 2311-2319

Shanks, A. L. (1983). Surface slicks associated with tidally forced internal waves may transport pelagic larvae of benthic invertebrates and fishes shoreward. Mar. Ecol. Prog. Ser. 13: 311-315

Shanks, A. L. (1985). Behavioral basis of internal-wave induced shoreward transport of megalopae of the crab Pachygrapsus crassipes. Mar. Ecol. Prog. Ser. 24: 289-295

Steger, R. (1987). Effects of refuges and recruitment on gonodactylid stomatopods, a guild of mobile prey. Ecology 68: $1520-1533$

Templeman, W. (1948a). Growth per moult in the American lobster. Bull. Nfld Govt Lab. 18: 26-48

Templeman, W. (1948b). Body form and stage identification in the early stages of the American lobster. Bull. Nfld Govt Lab. 18: $12-25$

Wahle, R. A. (1990). Recruitment, habitat selection, and the impact of predators on the early benthic phase of the American lobster (Homarus americanus Milne Edwards). $\mathrm{Ph} . \mathrm{D}$. dissertation, University of Maine, Orono

Wahle, R. A., Steneck, R. S. (1991). Recruitment habitats and nursery grounds of the American lobster, Homarus americanus: a demographic bottleneck? Mar. Ecol. Prog. Ser. 69: 231-243

Wilder, D. G. (1953). The growth of the American lobster (Homarus americanus). J. Fish. Res. Bd Can. 10: 371-412

Yashimura, T., Yamakawa, H. (1988). Microhabitat and the behavior of settled pueruli and juveniles of the Japanese spiny lobster Panulirus japonicus at Kominato, Japan. J. crust. Biol. 8: 524-531

Manuscript first received: February 14, 1991

Revised version accepted: September 20, 1991 